\title{
ENTRE RISCOS E DESINFORMAÇÃO: A UTILIZAÇÃO DA NANOTECNOLOGIA NA INDÚSTRIA DE ALIMENTOS
}

\author{
Rafael Gonçalves Fernandes \\ Centro Universitário de Brasília - UniCEUB, Brasília. \\ rafaelfernandes.dto@gmail.com

\section{Liziane Paixão Silva Oliveira} \\ Centro Universitário de Brasília - UniCEUB, Brasília. \\ lizianepaixao@gmail.com
}

\begin{abstract}
RESUMO: A nanotecnologia utiliza as propriedades da matéria em nanoescala, cuja unidade de medida denomina-se de nanômetro $(\mathrm{nm})$, que corresponde a uma bilionésima parte de um metro. Nessa escala, os níveis de toxidade podem ser diferenciados e, quiçá, prejudiciais ao meio ambiente e a saúde dos consumidores. O presente artigo científico tem como objetivo abordar a temática na perspectiva jurídica, especificamente no viés consumerista e regulatório, visando esclarecer se a ausência de normas específicas para a nanotecnologia, no Brasil, dificulta a concretização do direito do consumidor à informação, no que tange a presença de nanomateriais nos produtos alimentícios colocados no mercado de consumo. O método utilizado foi o hipotéticodedutivo e a pesquisa bibliográfica. Para tanto, fez-se uma breve contextualização dos aspectos técnicos pertinentes à nanotecnologia e da sua aplicação na indústria de alimentos, seguida da análise das políticas públicas brasileiras sobre (nano)regulação e do direito/dever à informação na seara consumerista.
\end{abstract}

PALAVRAS-CHAVE: Nanotecnologia. Nanoalimentos. Nanomateriais artificiais. Regulação de novas tecnologias. Direito do consumidor.

\section{Amid risks and misinformation: The use of nanotechnology in the food industry}

\begin{abstract}
Nanotechnology uses the properties of matter at the nanoscale, whose unit of measure is called nanometer (nm), equivalent to one billionth of a meter. On this scale, levels of toxicity may be different and, perhaps, detrimental to the environment and the health of consumers. The objective of this scientific article is to approach the issue from a legal perspective, specifically on the consumerist and regulatory bias, in order to clarify if the lack of specific norms for nanotechnology in Brazil makes it difficult to realize the consumer's right to information, regarding the presence of nanomaterials in food products placed on the consumer market. The method used was hypothetico-deductive and bibliographic research. For that, a brief contextualization of the technical aspects pertinent to nanotechnology and the application in the food industry was made, followed by the analysis of Brazilian public policies on (nano)regulation and the right/duty to information in the consumerist area.
\end{abstract}

KEYWORDS: Nanotechnology. Nanofoods. Engineered nanomaterials. Regulation of new Technologies. Consumer right.

\section{INTRODUÇÃO}

A nanotecnologia inaugurou uma fase revolucionária na produção de bens e serviços colocados à disposição do consumidor. É denominada de tecnologia emergente, pois tem inúmeras 
aplicações no mercado de consumo. Dentre as principais utilidades, destacam-se a sua incorporação nos produtos alimentícios, nos produtos farmacêuticos, nos produtos cosméticos e na indústria química em geral. ${ }^{1}$

Se, por um lado, a nanotecnologia atrai investimentos vultuosos e a atenção dos fornecedores e dos consumidores, impulsionando o setor econômico, por outro lado, gera dúvidas e preocupações quanto aos riscos envolvidos, tanto para a saúde do consumidor quanto para o meio ambiente. Em contrapartida, diversos produtos são comercializados em nível mundial, sem que o destinatário final seja informado, ao menos, sobre a existência de nanomateriais na composição desses produtos.

Nesse passo, a problemática deste artigo consiste em identificar se a ausência de uma regulação específica para os nanoalimentos ${ }^{2}$, no Brasil, dificulta a viabilização do direito à informação ao público consumidor. A abordagem do tema perpassa por uma breve contextualização da nanotecnologia, através da exposição de questões técnicas e históricas fundamentais, bem como da exemplificação da sua aplicação na indústria de alimentos. Em seguida, são apontados os riscos no consumo desses alimentos, de acordo com a literatura especializada. As políticas públicas brasileiras e os Projetos de Lei sobre a temática também fazem parte deste artigo científico, com o objetivo de compreender o estado da arte da nanotecnologia no cenário nacional. Além disso, os liames do direito/dever à informação completam a investigação no que tange às novas tecnologias alimentares.

A importância jurídica da temática está na franca ascensão da nanotecnologia e da sua aplicação na indústria alimentícia, sem a observância de qualquer marco regulatório específico, que estabeleça critérios de segurança na confecção, manipulação, transporte e descarte de nanomateriais. Somando-se a isso, a necessidade de facilitar o direito de escolha do destinatário final, através da identificação dos nanoalimentos que já circulam no mercado de consumo.

\section{A EVOlUÇÃo da NANOTECNOLOGia E SUA APLiCAÇÃo NA IN- DÚSTRIA DE ALIMENTOS.}

O termo nanotecnologia advém da fusão do prefixo grego "nannos", que significa anão, com as expressões "techne" e logos", compreendidas como ofício e conhecimento, respectivamente. A definição desse termo refere-se à compreensão e utilização das propriedades da matéria em nanoescala, cuja unidade de medida denomina-se de nanômetro (nm). Nessa dimensão, a matéria é invisível a olho nu ou através de microscópios convencionais (ópticos). Precisamente, a nanoescala equivale às medidas que vão de $1 \mathrm{~nm}$ até $100 \mathrm{~nm}$, sendo que cada nanômetro equivale a uma bilionésima parte de um metro. Tais medidas correspondem, por exemplo, ao tamanho de moléculas, vírus e átomos. (UNESCO, 2006, p. 5).

Os nanomateriais são o objeto de estudo da nanotecnologia e podem ser classificados em naturais, acidentais ou artificiais. Os nanomateriais naturais são aqueles que sempre existiram na natureza. Já os nanomateriais acidentais perfazem aqueles que decorreram de algum processo de interferência humana, mas não foram produzidos intencionalmente, por exemplo as nanopartículas emitidas pelo processo de combustão de veículos automotores. Por fim, os nanomateriais artificiais são resultado da manipulação humana intencional e com o objetivo de introduzi-los

\footnotetext{
Sobre a evolução da nanotecnologia ler Drexler (2006, p. 25-34) e Andersen (2011).

Cabe mencionar que a literatura especializada em nanotecnologia costuma utilizar a nomenclatura "nanoalimentos" e "nanofoods" para se referir aos produtos alimentícios que contêm algum nanomaterial artificial em sua composição ou que mantêm contato com embalagens e superfícies que foram produzidas com tais elementos.
} 
em algum processo científico/produtivo. Registra-se também que qualquer nanomaterial possui em sua composição nanopartículas. (HOHENDORFF; ENGELMANN, 2014, p. 422). A classificação exposta é adotada pela Comissão Europeia na recomendação 2011/696/UE, publicada em 18 de outubro de 2011. A recomendação traz, ainda, a definição de nanomaterial, como aquele que contém 50\% ou mais de nanopartículas com um tamanho entre $1 \mathrm{~nm}$ e $100 \mathrm{~nm}$, estabelecendo exceções que diminuem tal percentual, caso exista potenciais riscos ao ambiente, segurança, saúde ou a competitividade. (RECOMENDAÇÃO DA COMISSÃO, 2011, p. 38-39).

O presente artigo científico refere-se apenas aos nanomateriais artificiais, tendo em vista que são empregados intencionalmente nos processos produtivos pelos fabricantes. Dentre os setores que mais se destacam na utilização de nanomateriais estão: a engenharia de alimentos, a indústria de fármacos, a medicina, a biotecnologia e a eletrônica. A quantidade de produtos comercializados com essas substâncias já é notável, sendo que a sua aplicação concreta já pode ser identificada em alimentos, embalagens de alimentos, medicamentos, cosméticos, purificadores de água, embalagens, tintas, entre outros (CAPDEVILLE, 2009, p. 6-7).

Registra-se, também, que as definições expostas acima são as mais recorrentes e usuais no meio científico, mas não são unanimes, pois há divergência sobre os conceitos ligados à nanotecnologia. ${ }^{3}$ A justificativa para essa indeterminação advém, principalmente, da constante modificação e do rápido aprimoramento dessa tecnologia, combinada com a existência de diversos agentes no cenário global que estudam a temática. (ABDI, 2013, p.7).

Especificamente sobre o desenvolvimento histórico da nanotecnologia, atribui-se ao físico Richard Feynman os primeiros estudos sobre a viabilidade de manipulação da matéria em escala de átomos e moléculas individuais. Vencedor do Prêmio Nobel de Física de 1965, o pesquisador não chegou a utilizar o termo nanotecnologia, mas concedeu palestra em 1959 à Sociedade Americana de Física no Instituto de Tecnologia da Califórnia, cujo título “There's plenty of room at the bottom" ", indicava que o estudo da matéria em escala nanométrica revolucionaria o Mundo. (ABDI, 2013, p. 7).

O termo "nanotecnologia", contudo, foi utilizado pela primeira vez em 1974, por Norio Taniguchi, pesquisador da Universidade de Tóquio no Japão, para definir a capacidade de análise, construção e manipulação de materiais em escalas nanométricas na indústria eletrônica. $\mathrm{O}$ objetivo do pesquisador era construir dispositivos menores e mais velozes, utilizando componentes eletrônicos em chips de silício. Em seguida, Eric Drexler publicou, em 1986, o livro intitulado "Engines of creation: the comung era of nanotechnology", atribuindo uma conotação mais ampla à nanotecnologia. (BERGER FILHO, 2016, p. 140).

A exploração do potencial da nanotecnologia é tema transdisciplinar que envolve diversas ciências, tais como: a matemática, a física e a química. Também possui confluência com a biologia moderna, tecnologia da informação e com as ciências cognitivas, denominadas conjuntamente pela sigla NBIC. ${ }^{5}$ (SIMS BAINBRIGDE; ROCO, 2005, p. 2). Por outro lado, a relevância do estudo jurídico da nanotecnologia está na ampla utilização dessa tecnologia nos produtos inseridos no mercado de consumo, combinada com a baixa produção de estudos científicos sobre nanotoxidade.

A preocupação com o descontrole na utilização dessas substâncias em escala diferenciada, fez surgir uma base de dados denominada de "Nanotechnology Products Database" ou NPD. A plataforma visa rastrear e catalogar os produtos com nanomateriais, utilizando como

\footnotetext{
Sobre as diferentes definições ver Sellers (2009. p. 11-32) e Moses (2011, p. 42-48).

4 Tradução livre: "Há muito espaço lá embaixo".

5 A sigla corresponde às nomenclaturas das ciências em língua inglesa: "Nanotechnology, Information technology and Cognitive Science."
} 
fonte de dados as informações fornecidas voluntariamente pelos fabricantes. Estima-se que existam atualmente 8.462 produtos, produzidos por 2.056 companhias, em 56 países. (NPD, 2018).

Essa perspectiva, por sua vez, revela o crescimento exponencial e global dos investimentos em nanotecnologia, principalmente nos setores alimentar, eletrônico, farmacêutico e de saúde. De acordo com a Lux Research, no ano de 2012, o investimento mundial em nanotecnologia somou a quantia aproximada de 693 bilhões de dólares. Em 2015, o valor saltou para 2,95 trilhões de dólares, quantia representativa de $15 \%$ da produção global de bens manufaturados. (ABDI, 2010, p. 76). Estima-se que até 2025, os produtos nanotecnológicos alcançarão o mercado de massa em nível mundial (ROCO; MIRKIN; HERSAM, 2010, p. 43).

Há um forte interesse comercial na utilização da nanotecnologia nos bens de consumo, principalmente em setores que atingem o mercado de massa, tal como o setor de produção de alimentos. Especialistas indicam que a nanotecnologia tem potencial de realçar cores e sabores, melhorar a textura, otimizar suplementos vitamínicos e aumentar o prazo de validade de produtos alimentícios embalados ou in natura (HABER, STÄHLE, p. 2-4).

Os nanomateriais podem ser utilizados na própria composição do alimento e nas embalagens e pigmentos que o envolvem (ALDROVANDI; ENGELMANN, 2012, p. 690). Na indústria brasileira, é possível identificar algumas sociedades empresárias que desenvolvem nanotecnologia voltada aos alimentos. Uma dessas empresas comercializa biscoitos direcionados ao público infantil que contêm a nanotecnologia denominada "cooling". Tal tecnologia permite que o aroma mentolado do biscoito seja encapsulado através da utilização de nanopartículas que quando mastigadas proporcionam uma experiência diferenciada de frescor (EXAME, 2011). Existe também outra empresa brasileira que criou um pigmento esterilizante de nanoprata que triplica o prazo de validade dos alimentos. O produto já é exportado para o México e para os Estados Unidos da América (RYDLEWSKI, 2013).

A literatura especializada cita, ainda, outros benefícios da nanotecnologia aplicada aos alimentos, dentre eles estão: o desenvolvimento de alimentos funcionais que potencializam a absorção de aditivos vitamínicos; a eliminação de patógenos (vírus e bactérias) de origem alimentar; e, a proteção contra os raios UV e oscilações de temperaturas que acarretam mudanças de sabor, valor nutricional e validade do produto (SINGH et al., 2017). Alguns produtos que entram em contato ou armazenam alimentos também já contêm nanopartículas. É o caso de utensílios de cozinha, panelas, vasilhas e refrigeradores que possuem em sua composição nanopartículas à base de prata, cálcio, magnésio, zeólito e carbono que agem como esterilizantes. (NANOTECH PROJECT, 2018). Outros produtos direcionados ao setor alimentar também já são comercializados, mas não são rastreados ou divulgados, tendo em vista que as bases de dados de produtos com nanotecnologia são de adesão voluntária e há proteção legal das patentes e do segredo industrial (ANDERSEN, 2011, p. 682).

As inovações propostas pelas nanotecnologias e pelos nanoalimentos são extraordinárias, seja pela facilitação de diversos processos científicos e tecnológicos, seja pelo desenvolvimento socioeconômico que podem proporcionar. Existe um grande entusiasmo depositado nas inovações nanotecnológicas, principalmente pelos interesses mercantis envolvidos. Contudo, são diversas as preocupações com os riscos que essa tecnologia pode representar. Como será demonstrado abaixo, os nanomateriais artificiais tem características diferenciadas dos materiais em escala comum, e podem causar danos significativos à saúde humana. 


\section{OS RISCOS NO CONSUMO DE "NANOFOODS"}

Primeiramente, é importante ressaltar que as expressões "perigo", "incerteza" e "risco" não são sinônimas. Teresa Ancona Lopez (2010, p.24), afirma que o "perigo" consiste naquilo que ameaça ou traz insegurança para algo ou alguém, ou seja, há concretude e conhecimento científico sobre a potencialidade danosa de um evento. A expressão "incerteza", por outro lado, advém da literatura econômica e identifica os eventos que não possuem probabilidades conhecidas ou calculadas, devido à ausência de elementos objetivos aptos a avaliar o resultado de uma ação. (BERGER FILHO, 2016, p. 178). Já o "risco" consiste em um "perigo eventual", pois há certa previsibilidade na ocorrência do dano. (LOPEZ, 2010, p. 25).

Nesse passo, o risco possui uma vertente quantitativa que decorre da possibilidade de medir a ocorrência de um dano, mesmo que a probabilidade seja "abstrata e eventual". A incerteza também está presente no conteúdo do risco, pois sempre haverá certa dose de dúvida na concretização do dano. Berger (2016, p. 179) afirma que "a opção de separar risco e incerteza parte de uma preocupação pragmática ligada à necessidade de diferenciação do contexto para formular uma ação pretendida, seja ela a avalição de risco ou a formação de fóruns híbridos."

A visão "nativa” de risco, necessita da observância de autores da sociologia. (MOTTA, 2014, p. 20). Nesse ponto, Ulrich Beck (2011, p. 39), sociólogo alemão e autor de uma das obras mais conhecidas sobre o tema, afirma que o risco possui um elemento que remete ao "futuro". Tal elemento "baseia-se em parte na extensão futura dos danos atualmente previsíveis (...)" sendo que eles possuem relação "(...) com a antecipação, com destruições que ainda não ocorreram mas que são iminentes, e que nesse sentido, já são reais hoje.” (BECK, 2011, p. 39).

Ulrich Beck (2011, p. 40-41), afirma que vivemos em uma sociedade de risco marcada pela fase da "modernidade reflexiva", sendo que há um confronto entre o sucesso do progresso científico e industrial, com os efeitos negativos já perpetrados na sociedade, bem como dos riscos que se apresentam na atualidade apenas como uma "ameaça". Citando a comercialização de alimentos transgênicos e o aumento na utilização de agrotóxicos e de hormônios nas aves e bovinos, o autor afirma que a alimentação na "sociedade de risco" se transformou "(...) numa espécie de química alimentar implícita (...)." Para ele, a informação sobre os riscos no consumo de alimentos com alto teor de chumbo ou de metais pesados em alguns alimentos, alcança apenas parte da população que ainda está preparada para “driblar” tais riscos. (BECK, 2011, p. 42)

Para Raffaele de Giorgi, sociólogo italiano, o risco é uma construção concebida em sociedade e se constitui como a possibilidade de um evento ou invento ocasionar um dano. Para ele, o aperfeiçoamento ou a criação de novos mecanismos de segurança e de avaliação de riscos, gera novos riscos, pois o "aumento do risco significa, paradoxalmente, incremento das possibilidades de evitar o risco à medida que se disponha correr outros riscos." (DI GIORGI, 2007, p. 47,53). ${ }^{6}$

O campo científico que estuda os efeitos maléficos da nanotecnologia no meio ambiente e na saúde dos seres humanos, denomina-se de nanotoxicologia. No entanto, os estudos toxicológicos nessa área são escassos e relegados ao segundo plano. (BERGER FILHO, 2016, p. 167). Estudos já concluídos e realizados em ratos, peixes, células humanas e micro-organismos, apontam para a nocividade de alguns nanomateriais em organismos vivos.

\footnotetext{
6 A contextualização dessa passagem está nos avanços da medicina, que proporciona a cura ou tratamento de doenças, mas geram outros tipos de riscos. Por exemplo, os efeitos colaterais dos medicamentos. Nesse sentido, quanto mais se aumenta a proteção em relação a alguns riscos, mais nos submetemos a outros (DI GIORGI, 2007, p. 53). Aqui se encaixa a questão do tratamento de água realizado através de nanopartículas artificiais de prata que promete ser mais eficaz na eliminação de patógenos e impurezas. Haverá uma água mais limpa, entretanto, sujeita aos riscos de bioacumulação de nanopartículas nos órgãos e tecido do corpo humano e a contaminação do meio ambiente.
} 
Nesse sentido, as pesquisas realizadas indicam que a escala nanométrica de algumas nanopartículas artificiais agravam o risco de bioacumulação de substâncias nos órgãos e nos tecidos do corpo humano, podendo levar ao desenvolvimento de doenças. (SAVOLAINEN et al, 2010; VAN TASSEL, 2013, p. 453). Quando ingeridas, as partículas podem extravasar o trato digestivo e se alojar em outros órgãos, tais como coração, rim, baço, pulmão e cérebro. (TAGER; SALES, 2014, p. 17). Alterações nas funções do intestino também foram notadas, principalmente com a ingestão de nanopoliestireno, comumente encontrado em embalagens de alimentos. (BRADLEY et al, 2011, p. 603).

A literatura jurídica especializada afirma ainda que a absorção das nanopartículas artificiais pelo trato digestivo é diferente a depender das propriedades dessas substâncias, tal como o tamanho e a estrutura de superfície. Tais efeitos advêm da alta reatividade e mobilidade das nanopartículas que dificultam ou impossibilitam a remoção natural pelo corpo humano. Essas partículas se tornam mais "adesivas" que as partículas maiores. (TAGER; SALES, 2014, p. 18).

Existem indícios da possibilidade de desenvolvimentos de "nanopatologias", em decorrência da acumulação dessas substâncias no corpo humano por longos períodos, causando granulomas, lesões em tecidos e células e coágulos sanguíneos. (TAGER; SALES, 2014, p. 18). Dentre as nanopartículas artificiais que são citadas como causadoras de danos à saúde do consumidor estão a sílica, a prata, o dióxido de titânio, óxido de zinco e o carbono. Segundo o compilado de estudos científicos realizado em 2008, pela organização sem fins lucrativos "Amigos da Terra Austrália", a nano-nanosílica e a nano-prata podem causar toxidade hepática e a partir da sua absorção pelo trato gastrointestinal, causar bioacumulação e, também, a contaminação da placenta. O nano-dióxido de titânio pode danificar o DNA, prejudicar a função celular e o sistema imunológico. (CENTER FOR FOOD SAFETY, 2018, s.p.) O nano-óxido de zinco pode causar lesões no fígado, no pâncreas, no coração e no estômago. Já os nanotubos de carbono quando inalados podem causar mesotelioma, gerando efeitos parecidos com a exposição ao abesto. (HULL; BOWMAN, 2014)

Contudo, a comunidade científica carece de pesquisas sobre toxidade para a maioria das nanopartículas artificiais. (VAN TASSEL, 2013, p. 449). Especialistas afirmam que existem poucos testes adequados ao tamanho nanométrico dessas substâncias. Alguns deles alegam que a metodologia utilizada para os testes em escala macro não é suficiente para a avaliação da área de superfície e das propriedades químicas, físicas e biológicas dessas substâncias. Stern e McNeil (2008, p. 4) afirmam que os testes realizados são problemáticos porque envolveriam níveis de exposição às substâncias testadas que são muito elevadas e que não replicam a real exposição aos nanoprodutos.

Por fim, os investimentos em nanotoxocologia são muito aquém dos investimentos dedicados ao desenvolvimento de novos produtos. Em 2019, a NNI, agência norte-americana, publicou o relatório de previsão orçamentária indicando que serão utilizados U\$ 1.552 bilhões de dólares em desenvolvimento nanotecnólogo nos EUA. Apenas 83 milhões de dólares serão dedicados aos estudos de segurança, saúde e meio ambiente. (US COMMITTE ON TECHNOLOGY, 2018, p. 6.) . No cenário nacional não existem dados atualizados do investimento total em nanotecnologia ou nanotoxicologia. Estima-se que desde a criação do SisNano (Sistema Nacional de Laboratórios em Nanotecnologias) em 2012, tenha sido investimento cerca de R\$ 149 milhões de reais em desenvolvimento de produtos. Contudo, não há uma base de dados específica sobre os investimentos em pesquisa e em toxicologia nesse setor. (MCTIC, 2018, s.p.). 


\title{
3. AS PROPOSTAS REGULATÓRIAS PARA AS NANOTECNOLOGIAS NO BRASIL: HÁ UMA PREOCUPAÇÃO COM A SEGURANÇA ALIMEN- TAR?
}

\begin{abstract}
O panorama regulatório mundial revela que alguns países avançaram em áreas específicas da nanotecnologia, mas grande parte deles ainda não adota normas cogentes, apenas emite recomendações e guias de boas práticas. Nesse passo, o Brasil ainda não possui regulação dedicada à nanotecnologia e aos nanoalimentos, mas já debateu o tema no Congresso Nacional, através de quatro Projetos de Lei. Atualmente existem algumas iniciativas em execução no Poder Executivo, voltadas para a pesquisa científica e para os estudos de regulação.
\end{abstract}

Uma das justificativas para a omissão de regulação específica brasileira sobre essas novas tecnologias permeia a ideia de que o progresso tecnológico não pode ser freado com novas exigências e limitações legais. Além disso, há indicativos de que os interesses comerciais e industriais, consubstanciados na proteção de patentes ou direitos autorais dos nanomateriais, estão impedindo os avanços regulatórios. Nesse sentido, a Organização das Nações Unidas para a Ciência, Educação e Cultura (UNESCO), revelou a sua preocupação com a inexistência de regulação nesse grande setor e sustenta que existem interesses políticos e culturais que alimentam essa omissão. (2016, p. 20).

Cabe ressaltar que existem estudos científicos e articulações políticas que geram recomendações, cartilhas e informativos não obrigatórios sobre procedimentos de segurança. Trata-se, portanto, de normas denominadas de "não tradicionais", que revelam um conjunto de normas não formalmente cogentes formadas no interior de uma ou mais sociedades empresárias que “(...) preparam o caminho para o diálogo e o avanço na aceitação futura da obrigatoriedade dos compromissos e responsabilidades legais." (BERGER FILHO, 2016, p. 125).

Brevemente, o termo regulação é considerado gênero, representando a forma de produção do Direito. Há duas espécies de regulação, a regulação tradicional, considerada a norma acabada e juridicamente forte, e a regulação não tradicional, mencionada acima. Comumente, importam-se dois termos do Direito Internacional Público para identificar esses fenômenos regulatórios em outros campos. Utiliza-se o termo "hard law" para identificar as normas tradicionais, bem como o termo "soft law" para referir-se à regulação não tradicional. Conforme a literatura jurídica de Direito Internacional Público, a oposição dos termos:

[...] indicaria um contraste entre duas realidades coexistentes e que se auto-implicam: tanto se encontra presente o fator tempo (a hard law seria um produto acabado, ao final de uma evolução geracional ao longo do tempo, portanto, a norma terminada na sua inteireza, e soft, seria um vir a ser, um ato em potência, um ato de vontade dos Estados, que aspira a tornar-se uma norma), quanto o fator finalidade (na hard law, os Estados estabelecem obrigações jurídicas fortes, para serem efetivamente cumpridas, e na soft law existem normas jurídicas, mas seu cumprimento é meramente recomendado aos Estados, que podem, inclusive, não cumpri-las, sem que haja sanções aplicáveis aos inadimplentes) (SOARES, 2004, p.127).

No cenário brasileiro, o Poder Executivo adota algumas iniciativas que visam o desenvolvimento científico e a compreensão dos nanomateriais, visando uma futura regulação. Para a execução e controle dessas atividades, foram criados o Comitê Consultivo de Nanotecnologia (CCNano) e o Comitê Interministerial de Nanotecnologia (CIN), tendo sido instituído, neste último Comitê, um Grupo de Trabalho sobre a Regulação (GT-Reg). Além disso, adotou-se o Sistema Nacional de Laboratórios em Nanotecnologias (SisNANO), que identificou e estabeleceu centros nacionais de pesquisa em nanotecnologia e nanotoxicologia. (MCTI, 2014).

O CCNano, criado pela Portaria n. 441, de 24 de abril de 2014, do Ministério da Ciência, Tecnologia, Inovações e Comunicações (MCTIC), foi dissolvido pela nova Portaria n. 324, de 17 de janeiro de 2018, também editada pelo respectivo Ministério, cuja nomenclatura passou a

R. Jur. FA7, Fortaleza, v. 16, n. 2, p. 63-81, jul./dez. 2019 
ser "Comitê Consultivo de Nanotecnologia e Novos Materiais (CCNANOMAT)". Foram constituídos os novos membros e acrescida uma nova matéria ao comitê acerca do estudo de novos materiais. (MCTIC, 2018). O principal objetivo do CCNANOMAT é assessorar o MCTIC na alocação de recursos, na avaliação de programas, nas ações e projetos sobre nanotecnologia.

Já o Comitê Interministerial de Nanotecnologia (CIN), criado pela Portaria n. 510, de 10 de julho de 2012, pelo MCTIC, conta com a participação de diversos Ministérios e possui como principal função a assessoria, aprimoramento de políticas, diretrizes e ações relacionadas ao desenvolvimento das nanotecnologias no Brasil. Cabe ao CIN propor mecanismos de integração e coordenação, o planejamento e a implementação das nanotecnologias, bem como a recomendação de planos e programa e, ainda, a indicação de alocação de recursos financeiros para as áreas de pesquisa, desenvolvimento e inovação em nanotecnologias.

Através desses Comitês, o Brasil celebrou acordos internacionais com a Argentina, Japão e União Europeia, visando a cooperação e compartilhamento de estudos sobre as nanotecnologias e as experiências com regulações específicas. (MCTI, 2014).

O SisNANO, por sua vez, foi instituído pela Portaria n. 245, de 05 de abril de 2012, regulamentado pela Instrução Normativa n. 2, de 15 de junho de 2012, ambas do MCTIC. O sistema é formado por laboratórios credenciados e direcionados à pesquisa, desenvolvimento e inovação em nanotecnologia, sendo que há duas categorias de laboratórios: os laboratórios estratégicos vinculados ao Governo Federal, por exemplo, nas universidades públicas; e, os laboratórios associados, que podem ser da iniciativa privada. Há incentivos às pesquisas mediante a disponibilização de recursos públicos aos laboratórios credenciados. Atualmente, segundo o MCTIC, existem 26 laboratórios brasileiros vinculados ao SisNANO dedicados ao estudo das nanotecnologias (MCTIC, 2018).

Os grupos de trabalho e comitês criados pelo Poder Executivo, pautam suas atividades científicas na regulação internacional, especificamente nas atuais 107 normas técnicas da ISO sobre nanotecnologia (ISO, 2018), bem como no direito americano e no direito comunitário europeu. Nesse sentido, há uma tendência de colaboração e cooperação internacional nessa seara. Cita-se como exemplo o importante projeto mundial, já finalizado, voltado ao estudo das questões regulatórias da nanotecnologia, denominado de "NANoREG". O Projeto reuniu esforços de 16 países da Europa, bem como de outros países como Brasil, Japão, Austrália, Coréia do Sul e Canadá. (MCTI, 2014).

Da mesma forma, instituições como a Coordenação de Aperfeiçoamento de pessoal de Nível Superior (Capes) e o Conselho Científico e Tecnológico (CNPQ), possuem programas de fomento para áreas de concentração e linhas de pesquisa relacionadas à nanotecnologia, inclusive sobre a sua regulação (CALAÇA, 2005, p. 46).

Cabe ressaltar, ainda, que a Agência Nacional de Vigilância Sanitária (ANVISA), vinculada ao Ministério da Saúde e competente para regulamentar, controlar e fiscalizar os alimentos e os aditivos alimentares, também realiza estudos voltados à nanotecnologia, mas atualmente abrange apenas os setores de cosméticos e medicamentos. (OLIVEIRA; MARINHO; FUMAGALI, 2015, p. 40). Além disso, a Agência não realiza a distinção entre materiais de escala normal e de escala nanométrica no momento do registro dos produtos sujeitos à vigilância sanitária. Diante dessa lacuna, a ANVISA reconheceu em sua agenda regulatória 2015-2016, que a nanotecnologia encontra-se em “(...) uma lacuna regulatória em que há presença de assimetria de informações, bem como de insuficiência de referências metodológicas para análise dos eventuais riscos." (2014, p. 34). 
A ANVISA Instituiu em 10 de junho de 2013, o Comitê Interno de Nanotecnologia (CIN), através da Portaria n. 993, que possui a finalidade de elaborar diagnósticos institucionais da vigilância sanitária sobre a nanotecnologia e sobre os produtos que utilizam essa tecnologia, bem como o estudo das regulações internacionais e comunitárias sobre a temática. (ANVISA, 2013).

Como resultado dos trabalhos em nanotecnologia, a ANVISA publicou em 25 de março de 2014, o primeiro "Diagnóstico Institucional de Nanotecnologia da ANVISA", indicando os temas sujeitos a atuação regulatória. Demonstrou-se, também, a importância da disponibilização de informações fidedignas ao consumidor, bem como do estudo sobre segurança dos nanomateriais. O documento traz informativo sobre os produtos que estão registrados na ANVISA e que fazem menção ao uso de nanotecnologias: estimou-se que em 2014, existissem 599 produtos cosméticos, 10 medicamentos, 7 produtos para saúde, 1 produto alimentício. (CIN/ANVISA, 2014). Ocorre que essa menção sobre o uso de nanotecnologias nos produtos é facultativa para o requerente do registro, ou seja, não demonstra com fidelidade o real cenário dos produtos com nanomateriais.

Recentemente, a ANVISA lançou a segunda edição do programa denominado "Programa de Estudos Experienciais", que tem como objetivo aproximar os servidores que estudam a regulação com os pesquisadores que executam pesquisas científicas de diversas áreas, para que ao final se elabore regulações adequadas para cada campo. Dentre as áreas de interesse, a ANVISA elencou a nanotecnologia em materiais de uso em saúde como área prioritária, tendo em vista que consta na "Agenda Regulatória 2017-2020" como campo da ciência que merece atenção regulatória urgente (ANVISA, 2018). Ressalte-se que nessa edição do Programa não há menção à estudos sobre os nanoalimentos.

Além da ANVISA, havia até o ano de 2018, o Conselho Nacional de Segurança Alimentar e Nutricional (CONSEA) que funcionava como Órgão de assessoramento imediato da Presidência da República, com competência de formular, monitorar e avaliar as políticas públicas de segurança alimentar e nutricional no país. $\mathrm{O}$ objetivo principal era a realização do direito humano à alimentação adequada. Apesar do viés voltado a supressão de deficiências na alimentação de parte da população que não possui acesso ao alimento, pode-se afirmar que tal Conselho também poderia formular políticas voltadas ao controle da utilização de nanomateriais nos alimentos e nas embalagens produzidas no Brasil, conforme as competências descritas no art. $4^{\circ}$, incisos IV e V, da Lei n. 11.346/2006. Atualmente, cabe ao Ministério da Cidadania a criação e implementação da política nacional de segurança alimentar e nutricional, conforme o disposto nos art. 23, inciso II, e art. 85, inciso III, da Medida Provisória n. 870, de 01 de janeiro de 2019.

Os esforços realizados para o estudo e a regulação da nanotecnologia no Poder Executivo, foram compartilhados com o Poder Legislativo brasileiro que, através dos seus parlamentares, propuseram quatro Projetos de Lei, visando, ora a criação de uma política nacional de nanotecnologias, ora a rotulagem de produtos com nanomateriais.

O primeiro Projeto de Lei possuía como escopo a regulamentação de todas as áreas da nanotecnologia e foi proposto em 2005, pelo Deputado Edson Duarte (Projeto de Lei n. 5.076/ 2005). Visava a adoção de uma Política Nacional de Nanotecnologia, a criação de uma Comissão Técnica Nacional de Nanossegurança e de um fundo de desenvolvimento da nanotecnologia, mas foi arquivado em 2008, sob o fundamento de inflação regulatória no domínio do desenvolvimento tecnológico, bem como pelo monitoramento excessivo e restrições às pesquisas com nanomateriais. O Relator do Projeto argumentou que não haveria necessidade de um marco regulatório específico para as nanotecnologias, pois as leis vigentes no país já respondem aos problemas do desenvolvimento desta tecnologia, citando leis específicas, tais como: Leis n. 9.279/ 1996; 9.782/1999 e 11.105/2005. 
O segundo Projeto de Lei, proposto pelo Senador Tião Vianna (Projeto de Lei n. 131/ 2010), visou a alteração do Decreto-Lei n. 986/1969, que trata de normas básicas sobre alimentos, bem como a alteração da Lei n. 6.360/76, que dispõe sobre a vigilância sanitária, especificamente sobre drogas, insumos farmacêuticos, cosméticos e outras substâncias. O objetivo desse Projeto, que foi arquivado em 2013, era de determinar que os rótulos, embalagens, bulas, etiquetas e materiais publicitários de produtos com nanotecnologia, informassem e esclarecesse ao consumidor a presença de nanomateriais na composição do produto, através de símbolos, por exemplo. O principal argumento para o arquivamento consistiu na inexistência de estudos científicos que indiquem a nocividade da nanotecnologia no produto final.

O terceiro Projeto de Lei, cujo proponente foi o Deputado Sarney Filho (Projeto de Lei n. 5.133/2013, também abordava a regulamentação da rotulagem de produtos da nanotecnologia (nanomateriais) e de produtos que fazem uso da nanotecnologia (produto final que contêm nanomateriais). O Projeto foi arquivo em 31 de janeiro de 2019, nos termos do art. 105, do Regimento Interno da Câmara dos Deputados. O principal objetivo do Projeto, segundo a justificação elaborada pelo Proponente, era adequar a realidade da nanotecnologia ao Código de Defesa do Consumidor (CDC), especificamente do art. 6 do diploma, no que tange ao direito à informação dos consumidores. O Projeto trazia em sua justificação um item sobre os estudos de toxidade dos nanoalimentos e das embalagens que utilizam a nanotecnologia para conservar o alimento, ressaltando a importância de regular o setor e informar o consumidor sobre os possíveis danos à saúde e ao meio ambiente (Projeto de Lei n. 5.133/2013, p. 3-4).

O quarto e último Projeto, registrado sob o n. 6.741/2013, proposto também pelo Deputado Sarney Filho, dispunha sobre a Política Nacional de Nanotecnologia, a pesquisa, a produção e o destino de rejeitos e o uso da nanotecnologia no país. O Projeto foi apensando ao Projeto de Lei n. 5.133/2013, e também foi arquivado em 31 de janeiro de 2019. O texto de justificativa do Projeto, era voltado para a criação de um cadastro nacional que abrangesse todo o processo produtivo nanotecnológico, bem como a comercialização e o descarte dos produtos, fomentando, ainda, os estudos toxicológicos.

Nesse sentido, as tentativas de regulação de tecnologias emergentes, tal como a nanotecnologia, é tema polêmico e demasiadamente debatido no cenário nacional e internacional. Algumas tecnologias naturalmente envolvem um clamor social mais intenso e, até mesmo, a rejeição por um número considerável de pessoas, como ocorreu com os Organismos Geneticamente modificados (OGMs), gerando mobilização social. (APOTCKER, 2011, p. 82). A nanotecnologia alimentar, no entanto, ainda não sensibilizou ou mobilizou fortemente a sociedade civil. Tal situação pode estar ligada a uma percepção geral pró-ciência e tecnologia, somada à desinformação sobre o alcance e riscos dessa nova tecnologia em áreas afetas à saúde humana e ao meioambiente. (MCTI, 2014, p.22).

É certo que a cooperação internacional e a criação de regulação "soft law", mostra-se como caminho adequado à rápida globalização e expansão do comércio internacional dos nanoalimentos. Sendo necessário que o Brasil adote um marco regulatório para os nanoalimentos. Contudo, a garantia de funcionamento desse sistema de normas não tradicionais, perpassa por uma regulação estatal mínima, que indique os caminhos que os agentes estatais (pelas agências reguladoras, por exemplo) ou agentes privados devem seguir. Esse entendimento resulta da ideia de que o Estado não deve delegar ao setor privado toda a regulação sobre nanotecnologia, muito menos, assumir o controle total dessa área. (BERGER FILHO, 2016, p. 331).

Essa nova postura plural na regulação, que envolve normas elaboradas em cooperação por agentes que estão "dentro" e "fora" da "esfera regulatória do governo", denomina-se de "governança”. (ROCHA; LUZ apud. BERGER FILHO, 2016, p. 132). Nesse cenário, os agentes 
públicos e privados estabelecem, em conjunto, objetivos comuns para o desenvolvimento de parâmetros regulatórios adequados às novas tecnologias. Nesse sentido, Rocha e Luz afirmam:

\footnotetext{
[...] vai mais além do que o conceito de 'governo' porque engloba mecanismos de controle que se encontram fora da jurisdição e da esfera regulatória do governo; ela vai mais além da democracia porque implica noções de eficiência que servem à democracia e ao desenvolvimento concomitantemente. O Estado perde parte da vigência internacional, cedendo espaço às organizações não governamentais e à iniciativa privada, o que leva à substituição do conceito de governo pelo de governança. (ROCHA; LUZ apud. BERGER FILHO, 2016, p. 132).
}

Assim, é evidente que a nanotecnologia deve ser albergada pelo Direito e que este paute a criação de um marco regulatório nanotecnológico alinhado à preocupação do desenvolvimento tecnológico e científico sustentável, sem descuidar da importância de ações voltadas à preservação da segurança alimentar dos nanoalimentos.

Cabe mencionar que os riscos decorrentes de qualquer tecnologia emergente sempre existirão (BECK, 2011, p. 67), mas poderão ser amenizados com a observância, pelos agentes públicos e privados, responsáveis pela regulação e pela produção de nanoalimentos, de uma conduta ética pautada nos princípios da precaução, da dignidade da pessoa humana e da confiança, abarcando nesse último princípio, o direito à informação ao consumidor. (SILVEIRA; SANTOS, 2015, p. 185).

\section{O DIREITO À INFORMAÇÃO DOS CONSUMIDORES DE NANOALI- MENTOS}

Pesquisas empíricas sobre a percepção dos consumidores acerca dos nanoalimentos colocados no mercado de consumo, indicam uma possível rejeição dessa nova tecnologia alimentar. Estudos realizados na Alemanha apontam que grande parte dos consumidores ( $80 \%$ dos respondentes da pesquisa) não comprariam tais produtos. Por outro lado, o mesmo público, em sua maioria, compraria outros produtos com nanotecnologia, tais como roupas, aparelhos eletrônicos e acessórios (FEDERAL INSTITUTE FOR RISK ASSESSMENT, 2008, p. 18). Na Suíça (SIEGRIST et al., 2009) e Singapura (CHUAH et al., 2018), as pesquisas também revelam que há uma tendência de rejeição dos nanoalimentos, o principal motivo seria a ausência de informações ao público consumidor sobre aspectos essenciais e conceituais da nanotecnologia e sobre os riscos envolvidos.

Outro fator significativo que impacta o consumo de alimentos com novas tecnologias, consiste em sua "naturalidade perceptível" (SIEGRIST et al., 2009). Até mesmo o público que compreende as aplicações da nanotecnologia nos alimentos, tende a limitar o consumo desses produtos, pois há uma preferência pelos itens considerados "naturais" (FEDERAL INSTITUTE FOR RISK ASSESSMENT, 2010, p. 90-91).

Ocorre que mesmo diante de uma possível rejeição, os nanoalimentos já circulam silenciosamente no mercado de consumo, sem que o consumidor saiba quais ingredientes em nanoescala podem representar algum risco à sua saúde e ao meio ambiente. Assim, é necessário compreender se no cenário brasileiro há possibilidade de informar o consumidor sobre a presença de nanomateriais nos alimentos, mesmo diante da ausência de uma regulação específica, bem como se existe uma violação do direito/dever à informação nesse caso concreto.

O direito à informação tem dimensão polissêmica, possuindo campos distintos de aplicação, tais como: direito da comunicação (Constituição da República Federativa do Brasil de 1988 - CRFB/88, artigo $5^{\circ}$, incisos IV, XVI e XXXIII); direito ao acesso de informações públicas (Lei 
n. 12.527/2011); e, direito à informação do consumidor (CDC). Contudo, para discorrer sobre a problemática exposta, o direito à informação será delimitado na vertente consumerista.

A aplicação do direito à informação no direito do consumidor perfaz um direito fundamental, pois é uma das facetas da proteção do consumidor, descrita no art. $5^{\circ}$, inciso XXXII, da CRFB/88. Constitui-se como um dos direitos mais importantes e básicos do consumidor. A previsão específica está contida no art. $6^{\circ}$, inciso III, do Código de Defesa do Consumidor (CDC), prelecionando que é direito do consumidor: "III - a informação adequada e clara sobre os diferentes produtos e serviços (...), bem como sobre os riscos que apresentem”.

A literatura jurídica consumerista considera o direito à informação e o dever à informação, reflexos do princípio da transparência, ligando-os, também, ao princípio da vulnerabilidade do consumidor. Trata-se de instrumento de reequilíbrio e busca da igualdade na relação de consumo, tendo em vista que o consumidor não possui conhecimento técnico acerca do produto que adquire, principalmente daqueles produtos que possuem um nível científico e/ou tecnológico elevados. (CAVALIERI FILHO, 2014, p. 103).

Menciona-se, ainda, que o direito do consumidor à informação não se exaure em si mesmo, ou seja, não visa apenas fornecer as informações necessárias ao consumidor, mas pretende preservar outro direito básico, que é o da escolha livre e consciente. (CAVALIERI, 2014, p. 104). O direito de escolha ou o "consentimento informado", é exercido quando o consumidor possui todas as informações adequadas para satisfazer às expectativas pessoais, tais como: segurança, saúde, estilo de vida, religião, entre outras.

Nesse passo, a informação apenas restará assegurada ao consumidor se o fornecedor exercer adequadamente o seu dever de informar. É um ônus que deriva do princípio da boa-fé objetiva, estabelecida no CDC. Apesar disso, não se trata apenas de um dever anexo, mas de um dever principal na relação de consumo, em razão da elevação do direito à informação ao nível de direito fundamental. (LÔBO, 2000, p. 327).

Cabe mencionar que o art. 31 do CDC, preleciona que o fornecedor tem o dever de fornecer informações claras, precisas e ostensivas, bem como de todos os elementos obrigatórios, somados à exigência de informar sobre os riscos que os produtos podem causar à saúde ou a segurança dos consumidores. (NUNES, 2017, p. 203). Nesse sentido, o CDC trouxe três artigos sobre a proteção da saúde e segurança do consumidor, fixando critérios que deverão ser observados pelo fornecedor, visando preservar a vida, segurança e direito de escolha do consumidor.

Primeiramente, o artigo $8^{\circ}$ dispõe que "os produtos e serviços colocados no mercado de consumo não acarretarão riscos à saúde ou segurança dos consumidores". Contudo, tal disposição contém uma exceção quanto aos produtos que por sua natureza e fruição geram riscos considerados normais e previsíveis, desde que o fornecedor informe adequadamente o consumidor. Em outra senda, o artigo $9^{\circ}$ permite que produtos e serviços potencialmente nocivos ou perigosos sejam colocados no mercado de consumo, contanto que a periculosidade seja inerente ao produto ou serviço e que haja informação adequada e ostensiva ao consumidor. Sendo o fornecedor detentor de informações privilegiadas sobre os potenciais riscos de determinado produto ou serviço, deve compartilhar tais dados com o consumidor. Por último, o artigo 10, proíbe a colocação no mercado de consumo de produtos ou serviços com alto grau de periculosidade ou nocividade. ${ }^{7}$

7 Cumpre ressaltar que a CFRB/88, trouxe em seu art. 220, parágrafo $4^{\circ}$, uma disposição limitadora no comércio e publicidade de alguns produtos maléficos à saúde humana. Nesse rol constam o tabaco, as bebidas alcoólicas, os agrotóxicos, os medicamentos e as terapias, cabendo a lei infraconstitucional estabelecer regras limitadoras específicas. Trouxe, ainda, uma disposição importante acerca do direito à informação do consumidor, qual seja: a obrigatoriedade da presença de advertências sobre os riscos no rótulo do produto. (LOPES, 2008, p. 88). O CDC não elencou 
Os produtos naturalmente geram riscos ao consumidor. Não existem produtos ou serviços totalmente seguros. O Direito do Consumidor não tem o objetivo de eliminar todos os riscos e perigos do mercado, pois tal anseio seria impossível de ser concretizado. (BENJAMIN, 2017, p. 182). Para distinguir tais riscos e perigos, a literatura jurídica utiliza uma categorização que consiste em três tipos de periculosidade. Nesse rol estão a periculosidade inerente, a periculosidade adquirida e a periculosidade exagerada.

A periculosidade inerente refere-se ao risco que é intrínseco à coisa, decorre da própria natureza, modo de funcionamento ou qualidade do bem. Para Benjamin (2017, p. 185), “(...) para que a periculosidade seja reputada inerente, dois requisitos devem estar presentes: a normalidade e a previsibilidade. Têm eles a ver com a expectativa legítima dos consumidores." São exemplos de produtos com periculosidade inerente: a faca afiada, agrotóxicos e medicamentos com contraindicação. Embora o produto seja capaz de causar acidentes, a periculosidade já é previsível pelo consumidor. Cabe ao fornecedor informar ao consumidor sobre tais riscos, podendo por eles ser responsabilizado caso não cumpra o dever de informar de forma adequada e ostensiva (art. $9^{\circ}, \mathrm{CDC}$ ), hipótese que se configurará o defeito de comercialização devido à informação deficiente. (CAVALIERI, 2014, p. 317).

A periculosidade adquirida surge com o defeito do produto ou do serviço, mas que originalmente não acarretariam riscos superiores aqueles esperados pelos consumidores. Benjamin (2017, p. 186) explica que "a característica principal da periculosidade adquirida é exatamente a sua imprevisibilidade para o consumidor. É impossível (ou quando possível, inútil) qualquer modalidade de advertência. Já que não tem condão de eliminá-la."

A periculosidade exagerada abarca os produtos ou serviços que possuem um alto potencial danoso para o consumidor. Nessa categoria a presença de informações ostensivas e adequadas não impede o dano. Por esse motivo, tais bens não podem, em hipótese alguma, ser inseridos no mercado de consumo. "São considerados defeituosos por ficção. É o caso de um brinquedo que apresente grandes possibilidades de sufocação da criança. A informação, nestes casos, é de pouca valia em decorrência dos riscos excessivos do produto ou serviço.” (BENJAMIN, 2017, p. 187).

O CDC não proibiu a circulação de produtos que possuam periculosidade inerente, pois muitos bens inseridos no mercado de consumo possuem um certo grau de riscos esperados pelos consumidores. (MARQUES, 2011, p. 815). Contudo, o Diploma veda a colocação de bens ou serviços no mercado que possuam periculosidade adquirida e periculosidade exagerada. A justificativa está na grande desproporção entre os benefícios auferidos pelo consumidor e os perigos e riscos decorrentes da sua utilização.

Nesse sentido, as nanotecnologias adequam-se ao disposto no artigo $9^{\circ}$ do CDC, tendo em vista que os produtos produzidos com nanomateriais podem ser encaixados na categoria da periculosidade inerente. Essa afirmação pode ser obtida através dos estudos científicos que concluíram que alguns nanomateriais, submetidos aos estudos toxicológicos, podem causar danos à saúde humana e ao meio-ambiente. (ENGELMANN, 2015, p. 363). É nesse sentido que a baixa produção de pesquisas sobre nanotoxicologia não pode eximir o fornecedor de agir com cautela na inserção desses elementos nos produtos ou serviços dispostos ao consumidor, muito menos desobrigar a constante busca por informações sobre os riscos advindos da nanotecnologia.

O fornecedor que deixa de informar o consumidor sobre os riscos da nanotecnologia está, em tese, sujeito a responsabilização pela falta de informação sobre o produto potencialmente

um rol especifico de produtos, mas ampliou a aplicação do dispositivo constitucional utilizando a classificação de "nocividade" e "perigosidade" para identificar os potenciais riscos. 
nocivo e perigoso. Como afirmado acima, o fornecedor não responderá pela periculosidade do produto, mas sim pelo defeito de comercialização na ausência de informações adequadas. Dessa forma, é imprescindível que o fornecedor que manipula nanomateriais artificiais para aplicação no alimento ou em sua embalagem adote testes de segurança alimentar, visando incluir no mercado de consumo apenas aqueles produtos que não ofereçam riscos à saúde do consumidor e ao meio ambiente (SINGH et al., 2017).

Já existem tentativas de rotulagem de nanoalimentos, com o objetivo de informar os consumidores sobre a presença de nanomateriais artificiais em tais produtos. Por exemplo, a União Europeia adotou um Regulamento sobre a obrigatoriedade de indicar no rótulo do produto alimentício quais foram os nanomateriais artificiais utilizados em sua composição. O Regulamento Delegado (UE) n. 1169/2011 do Parlamento Europeu e do Conselho, relativo à prestação de informação aos consumidores sobre os gêneros alimentícios, disserta no art. $18^{\circ}$, n. 3 , que "os ingredientes contidos sob a forma de nanomateriais artificiais devem ser claramente indicados na lista de ingredientes. A palavra «nano» entre parêntesis deve figurar a seguir aos nomes destes ingredientes." (UNIÃO EUROPEIA, 2011, p. 31).

Contudo, a aplicação do Regulamento se revelou complexa, pois há uma indefinição sobre o conceito de nanomateriais artificiais seja na União Europeia, seja na comunidade científica mundial. Nesse passo, existe uma incerteza sobre quais ingredientes devem ser obrigatoriamente rotulados como "nanomateriais artificiais" (SALVI, 2015, p. 188).

Diante disso, o Regulamento mencionado acima foi parcialmente reformulado pelo Regulamento Delegado (EU) n. 1363/2013 da Comissão de 12 de dezembro de 2013 (UNIÃO EUROPEIA, 2013, p. 27-28). O novo diploma adota a definição de nanomaterial artificial já constante na Recomendação n. 2011/696/EU. A tentativa de alcançar um conceito coerente e atualizado, revela que a União Europeia importa definições técnicas de normas elaboradas por entidades privadas especializadas em normatização, seja pelo Comitê Europeu de Normalização (European Committee for standardisation - CEN), seja pela Organização Mundial de Normalização (International Organization for Standardization - ISO).

Apesar do Brasil não possuir regulação para os nanoalimentos, o grande exemplo nacional sobre a importância da informação ao consumidor acerca das incertezas de novas tecnologias empregadas na indústria alimentícia, foi a discussão regulatória dos OGMs. Os principais fundamentos para que se adotasse um marco regulatório específico basearam-se no princípio da precaução e da necessidade de se adotar regras específicas sobre segurança, fiscalização, manipulação, transporte e descarte dos organismos geneticamente modificados. A Lei de Biossegurança brasileira (Lei 11.105/2005), que regula os OGMs, trouxe um grande aparato administrativo para controlar os atos de pesquisa e comercialização.

Assim, para se iniciar qualquer estudo científico com transgenia, tornou-se obrigatório reivindicar a autorização da Comissão Técnica Nacional de Biossegurança (CNTbio) ou, em alguns casos, do Conselho Nacional de Biossegurança (CNB). A Lei trouxe ainda, no seu art. 40, o dever do fornecedor de informar ao consumidor quais são os alimentos que foram produzidos com OGMs ou seus derivados, através de um símbolo específico impresso no rótulo do produto. A rotulagem dos OGMs já havia sido regulada com base no CDC e na antiga lei de biossegurança (Lei n. 8.974/1995), nos termos do Decreto n. 4.680/2003. (VARELLA; BARROS-PLATIAU, 2005, p.40).

A informação adequada ao consumidor sobre a presença e potenciais riscos dos nanomateriais também pode instruir e incentivar o descarte adequado dos produtos e resíduos que contêm essa tecnologia, tendo em vista que a Política Nacional de Resíduos Sólidos prevê ações mais 
pró-ativas por parte dos agentes privados. O desenvolvimento dessa política depende da divulgação de informações ao consumidor, para que este possa compreender os riscos e colaborar com a melhoria da qualidade ambiental (EFING; KALIL, 2016, p. 34-36).

Nesse sentido, a informação é o nascedouro do conhecimento sobre a segurança do produto ou serviço, sendo que pode ser considerada a melhor ferramenta para combater as dúvidas sobre os riscos e perigosos das nanotecnologias. Perfazendo, também, um mecanismo de expressão dos princípios da precaução e prevenção. (LOPES, 2010, p. 191).

\section{CONCLUSÃO}

O Brasil atualmente não possui nenhuma regulação específica para as nanotecnologias, mas executa alguns programas institucionais que incentivam a pesquisa científica nessa área. Especificamente, o Poder Executivo tem um aparato administrativo voltado à distribuição de recursos financeiros e ao monitoramento de alguns laboratórios que desenvolvem nanomateriais artificiais. Contudo, não existem mecanismos específicos de controle comercial pelos órgãos responsáveis pela segurança alimentar e sanitária dos alimentos. No Poder Legislativo, identificou-se quatro projetos de lei já arquivados, que haviam sido propostos no Senado e na Câmara dos Deputados. Atualmente não existem novas iniciativas legislativas em trâmite.

A conduta omissiva dos agentes responsáveis pela regulação e pela fiscalização dificulta a concretização do direito à informação do consumidor, pois há pouco interesse dos fabricantes em inserir voluntariamente determinados elementos informativos nos produtos alimentícios. Dessa forma, o tratamento jurídico dado pela legislação brasileira às tecnologias emergentes, não consegue responder satisfatoriamente aos liames específicos do desenvolvimento e comercialização de nanoprodutos, apesar de nortear a aplicação de normas gerais sobre o direito à informação do consumidor.

Assim como no caso dos alimentos que incorporavam os OGMs em sua composição, há a necessidade de uma complementação normativa por meio de uma regulação mínima sobre as nanotecnologias, que estabeleça: (i) a obrigatoriedade da distribuição da informação sobre a presença de nanomateriais dentro da cadeia de produção dos alimentos; (ii) a obrigatoriedade de registro desses produtos em organismos de controle; (iii) o gerenciamento de riscos nanotecnológicos; e (iv) os meios adequados para efetivar o direito à informação ao consumidor, seja através de rotulagem, rastreamento, publicidade ou outro meio hábil;

Por fim, entende-se que qualquer regulação que preveja apenas a rotulagem de produtos alimentícios com nanomateriais, não surtirá o efeito desejado de informar de maneira ostensiva o consumidor, pois é necessária a formulação de políticas públicas prévias que apresente a nanotecnologia aos consumidores brasileiros, revelando qual é a sua aplicação no mercado de consumo e quais são os riscos e benefícios na sua utilização.

\section{REFERÊNCIAS}

AGÊNCIA BRASILEIRA DE DESENVOLVIMENTO INDUSTRIAL. Estudo prospectivo nanotecnologia. Brasília: ABDI, 2010.

AGÊNCIA BRASILEIRA DE DESENVOLVIMENTO INDUSTRIAL. Relatório de acompanhamento setorial - nanotecnologia na área da saúde: Mercado, segurança e regulação. Brasília: ABDI, 2013. 
AGÊNCIA NACIONAL DE VIGILÂNCIA SANITÁRIA. Diagnóstico Institucional de Nanotecnologia da ANVISA. 2014. Disponível em: http://portal.anvisa.gov.br/documents/219201/ 219401/Diagn\%25C3\%25B3stico\%2BInstitucional\%2Bde\%2BNanotecnologia\%2B-

\%2BCIN\%2B2014\%2B-\%2BDicol.pdf/36a88213-b849-473d-97c1-fdccb6a2f84c. Acesso em: 14 jan. 2019.

AGÊNCIA NACIONAL DE VIGILÂNCIA SANITÁRIA. Tendências: Anvisa quer conhecer tecnologias inovadoras na Saúde. 2018. Disponível em: http://portal.anvisa.gov.br/rss/-/asset_ publisher/Zk4q6UQCj9Pn/content/id/4456165. Acesso em: 14 jan. 2019.

AGÊNCIA NACIONAL DE VIGILÂNCIA SANITÁRIA. Agenda regulatória 2015/2016. 2014. Disponível em: http://portal.anvisa.gov.br/documents/10181/2719431/Manual\%2Bde\%2BOrienta\%C3\%A7\%C3\%B5es\%2B-\%2BJPC_rev_TRC.pdf/e69e79e4-bd6340ab-b45e-f331c41a19ed. Acesso em: 04 jul. 2018.

ALDROVANDI, Andréa; ELGENMANN, Wilson. O direito à informação sobre a toxidade dos nanoalimentos. Revista Pensar, Fortaleza, v. 17, n. 2, p. 672-698, jul./dez. 2012.

ANDERSEN, Maj Munch. Silent innovation: corporate strategizing in early nanotechnology evolution. Journal of Technology Transfer, p. 680-696, vol. 36, n. 6, 2011.

APOTCKER, Arnauld. Ciência e democracia: o exemplo dos OGMs. In: ZANONI, Magda; FERMENT, Gilles. (orgs.) Transgênicos para quem? Agricultura, ciência e Sociedade. Brasília: MDA, 2011. p.82-92.

ARCOR lança biscoito com nanotecnologia. Exame, 2011. Disponível em: https://exame.abril.com.br/marketing/arcor-lanca-biscoito-com-nanotecnologia/. Acesso em: 13 nov. 2018.

BECK, Ulrich. Sociedade de risco. Trad. Sebastião Nascimento. São Paulo: Editora 34, 2011.

BENJAMIN, Antonio Herman V. Fato do produto e do serviço (capítulo VI). In: BENJAMIN, Antonio Herman V.; MARQUES, Cláudia Lima; BESSA, Leonardo Roscoe. Manual de Direito do Consumidor. 8. ed. São Paulo: Revista dos Tribunais, 2017.

BERGER FILHO, Aírton Guilherme. A governança dos riscos das nanotecnologias e o princípio da precaução: um estudo a partir da teoria dialética da rede. Tese (Doutorado em Direito). Universidade do Vale do Rio dos Sinos, São Leopoldo, 2016.

BRADLEY, E et al. Applications of nanomaterials in food packaging with a consideration of opportunities for developing countries. Trends Food Science and Technology. v. 22. n. 11. P. 603-610, 2011.

CALAÇA, Irene. Nanotecnologia: subsídios para o acompanhamento do tema. Revista Brasileira de Inteligência. n. 9. Brasília: ABIN, maio 2005.

CAPDEVILLE, Anaïs. Nanomateriaux et protection du consommateur. Dissertação. (Mestrado em direito do consumidor e concorrência). Université de Montpellier I, França, 2009.

CAVAliERI FILHO, Sergio. Programa de direito do consumidor. 4. ed. São Paulo: Atlas, 2014.

CHUAH, A. et al. Label it or ban it? Public perceptions of nano-food labels and propositions for banning nano-food applications. Journal of Nanoparticle research, v. 20. Ano 2, fev. 2018.

DREXLER, Kim Eric. Nanotechnology: From Feynman to Funding. In: HUNT, Geoffrey; MEHTA, Michael. Nanotechnology: risk, ethics and law. Londres: Earthscan, 2006, p. 25-34. 
EFING, Antônio Carlos KALIL, Ana Paula Maciel Costa. Consumo Consciente: o anverso subjacente da Política Nacional de Resíduos Sólidos. Revista Jurídica da FA7. v. 13, n. 2, p. 25 37, jul./dez. 2016.

ENGELMANN, Wilson; MARTINS, Patrícia Santos. As Normas ISO e as nanotecnologias: entre a autorregulação e o pluralismo jurídico. São Leopoldo: Karywa, 2017.

ENGELMANN, Wilson. A utilização de nanopartículas de zinco na indústria do plástico: o consumidor estará seguro? Revista de Direito do Consumidor, v. 102. ano. 24. p. 355-385. São Paulo: RT, nov.-dez. 2015.

FEDERAL INSTITUTE FOR RISK ASSESSMENT. Public Perceptions about nanotechnology: Representative survey and basic morphological-psychological study. Berlin: BfR, 2008.

FEDERAL INSTITUTE FOR RISK ASSESSMENT. BfR Delphi Study on nanotechnology: Expert survey of the use of nanomaterials in food and consumer products. Berlin: BfR, 2010.

FEYNMAN, Richard P. Há mais espaços lá embaixo: um convite para penetrar em um novo campo da Física. Brasil: SBPC, 2002. Disponível em: http://www.comciencia.br/reportagens/ nanotecnologia/nano19.htm. Acesso em: 21 jun. 2018.

HABER, Bernd; STÄHLE, Sieglinde. Nanotechnology in foods - fact or fiction? EFLL - European Food and Feed Law Review, v. 6 n. 3, p. 400-4006, Berlin: Lexxion, 2008.

HOHENDORFF, Raquel Von; ENGELMANN, Wilson. Nanotecnologias aplicadas aos agroquímicos no Brasil: a gestão dos riscos a partir do Diálogo entre Fontes do Direito. Curitiba: Juruá, 2014.

HULL, Matthew S.; BOWMAN, Diana M. Nanotechnology Environmental Health and Safety: Risks, Regulation, and Management. 2.ed., EUA: Elsevier, 2014.

INTERNATIONAL ORGANIZATION FOR STANDARDIZATION. ISO TS 800004-1:2015: Nanotechnologies - Vocabulary - Part 1: Core terms. Suiça, 2015. Disponível em: https://www.iso.org/obp/ui/\#iso:std:iso:ts:80004:-1:en. Acesso em: 21 jun. 2018.

INTERNATIONAL ORGANIZATION FOR STANDARDIZATION. Standars catalogue: nanotechnologies. Suiça, 2018. Disponível em: https://www.iso.org/committee/381983/x/catalogue/. Acesso em: 21 jun. 2018.

LÔBO, Paulo Luiz Netto. A informação como direito fundamental do consumidor. Revista de Direito do Consumidor, São Paulo, n. 37, p. 59-76, jan./mar. 2001.

LOPEZ, Teresa Ancona. Nexo causal e produtos potencialmente nocivos - A experiência brasileira do tabaco. São Paulo: Quartier Latin, 2008.

LOPEZ, Teresa Ancona. Princípio da precaução e evolução da responsabilidade civil. São Paulo: Quartier Latin, 2010.

MARCHANT, Gary E. et al. Big issues for small stuff: nanotechnology regulation and risk management. Jurimetrics: The Journal of Law, Science \& Technology, v. 52, n. 3, p. 243-277, 2012.

MARQUES, Cláudia Lima. Contratos no Código de Defesa do Consumidor: o novo regime das relações contratuais. São Paulo: Revista dos Tribunais, $8^{a}$ ed. 2016.

MCTI. Diálogos setoriais entre Brasil e União Europeia: Regulação da nanotecnologia no Brasil e na União Europeia. Brasília: MCTI, 2014. 
MCTIC. Para ministro, investimento em nanotecnologia pode acelerar desenvolvimento econômico. MCTIC. Brasília, 22 maio 2019. Disponível em: http://www.mctic.gov.br/mctic/opencms/salaImprensa/noticias/arquivos/2018/10/Para_ministro_investimento_em_nanotecnologia_ pode_acelerar_desenvolvimento_economico_do_pais.html. Acesso em: 10 jun. 2019.

MOSES, Lyria Bennett. Regulating beyond nanotecnhology.in: IEEE Technology and Society Magazine, vol. 30, n. 3, p. 42-48, 2011.

MOTTA, Renata. Risco e modernidade: uma nova teoria social? Revista Brasileira de Ciências Sociais, v. 29, n. 86, out. 2014.

NANOPARTICLES. U.S. National Library of Medicine. Disponível em https://clinicaltrials.gov/ct2/results?recrs $=\&$ cond $=\&$ term $=$ nanoparticles $\&$ cntry $=\&$ state $=\&$ city $=\&$ dist $=. \quad$ Acesso em: 02 jun. 2018.

NANOTECHNOLOGY PRODUCTS. Nanotechnology Products Database (NPD). Disponível em: https://product.statnano.com/. Acesso em: 01 jun. 2018.

NUNES, Rizzatto. Curso de direito do consumidor, 11 a edição. São Paulo: Saraiva, 2017.

OLIVEIRA, Liziane Paixão Silva; MARINHO, Maria E. P. ; FUMAGALI, E. Nanomedicamentos e os desafios da Anvisa diante da inexistência de um marco regulatório no Brasil. Arel Faar - Revista Amazon's Research and Environmental Law, v. 3, p. 36-51, 2015.

PASCHOALINO, Matheus P.; MARCONE, Glauciene P. S.; JARDIM, Wilson. F. Os Nanomateriais e a Questão Ambiental. Revista Química Nova, v. 33, n. 2, p. 421-430, 2010.

ROCO, Mihail C.; MIRKIN, Chad A.; HERSAM, Martk C. Nanotechnology Research Directions for Societal Needs in 2020: Retrospective and Outlook. [S. 1.]: Springer, 2010, p. 43. Disponível em Acesso em: 15 nov. 2018

RYDLEWSKI, Carlos. Empresa paulista cria tecnologia que triplica o prazo de validade dos alimentos. Época Negócios, 2013. Disponível em: https://epocanegocios.globo.com/Informacao/Visao/noticia/2013/04/empresa-paulista-cria-tecnologia-que-triplica-o-prazo-de-validadede-alimentos.html. Acesso em: 04 jan. 2019.

SALVI, Laura. The EU's 'Soft Reaction' to Nanotechnology Regulation in the Food Sector. European food and feed law review, v. 10 n. 3. p. 186-193, 2015.

SAVOLAINEN, K. et al. Nanotechnologies, engineered nanomaterials and occupational health and safety - A review. Safety Science, v. 48. n. 8. [S. 1.]: Elsevier, Out. 2010.

SELLERS, Kathleen. Nanoscale materials: Definition and properties. in: SELLERS, Kathleen; MACKAY, Christopher; BERGESON, Lynn L. (et al.) Nanotechnology and the environment. Boca Raton: CRC Press, 2009, p. 11-32.

SIEGRIST, $\mathrm{M}$ et al. Acceptance of nanotechnology foods: a conjoint study examining consumers willingness to buy. British Food Journal, v. 111. N. 7, p. 660-668, 2009.

SILVEIRA, Vladmir Oliveira; SANTOS, Queila Rocha Carmona dos. Os potenciais riscos das nanotecnologias: informação e responsabilidade à luz do Código de Defesa do Consumidor. In: Revista de Direito do Consumidor, v. 97, ano 24, p. 173-197. São Paulo: RT, jan.-fev. 2015.

SIMS BAINBRIDGE, William; C. ROCO, Mihail. Managing Nano-Bio-Info-Cogno Innovations: Converging Technologies in Society. Dordrecht: Springer, 2006.

SINGH, T. et al. Application of Nanotechnology in Food Science: Perception and Overview. Frontiers in Microbiology, v. 8. n. 1501, [S. 1.: s. n.], 2017. DOI: 10.3389/fmicb.2017.01501. 
SOARES, Guido F. da Silva. Curso de Direito Internacional Público. 2. ed. São Paulo: Atlas, 2004.

SOARES, Tânia Sofia Couto. Efeitos de nanopartículas de prata em neutrófilos humanos. (2014). Dissertação (Mestrado em Fármacia). Faculdade de Farmácia. Universidade do Porto. Porto, Portugal, 2014.

STERN, Stephan T.; MCNEIL, Scott E. Nanotechnology Safety Concerns Revisited. Toxicological Sciences, v. 101, n. 1, p. 4-21, jan. 2008.

TAGER, Jeremy; SALES, Louise. Way too little: our government's failure to regulate nanomaterials in food and agriculture. [s.1], Friends of the earth Australia, 2014.

The Project on Emerging Nanotechnologies. Nanotechproject, 2018. Disponível em: http://www.nanotechproject.org/cpi/browse/categories/food-and-beverage/. Acesso em: 04 jan. 2019.

UNESCO. Ética y política de la nanotecnología. Disponível em: https://unesdoc.unesco.org/ ark:/48223/pf0000145951_eng. Acesso em: 20 jul. 2018.

UNESCO. Nanotechnology is a growing research priority. 2016. Disponível em: http://www.unesco.org/new/en/media-services/single-view/news/nanotechnology_is_a_ growing_research_priority/. Acesso em: 10 jun. 2018.

UNIÃO EUROPEIA. Regulamento Delegado n. 1169/2011 do Parlamento Europeu e do Conselho, relativo à prestação de informação aos consumidores sobre os gêneros alimentícios. Disponível em: https://eur-lex.europa.eu/legal-content/PT/TXT/PDF/?uri=CELEX:32011R1169\&from=ET. Acesso em: 02 jan. 2019.

UNIÃO EUROPEIA. Recomendação da Comissão de 18 de outubro de 2011 sobre a definição de nanomaterial, (2011/696/UE). Disponível em: https://eur-lex.europa.eu/LexUriServ/LexUriServ.do?uri=OJ:L:2011:275:0038:0040:PT:PDF. Acesso em: 03 jan. 2019.

UNIÃO EUROPEIA. Regulamento Delegado n. 1363/2013 da Comissão que altera o Regulamento (UE) n.o 1169/2011 do Parlamento Europeu e do Conselho relativo à prestação de informação aos consumidores sobre os géneros alimentícios, no que se refere à definição de nanomaterial artificial. Disponível em: https://eur-lex.europa.eu/LexUriServ/LexUriServ.do?uri=OJ:L:2013:343:0026:0028:PT:PDF. Acesso em: 02 jan. 2019.

US COMMITTE ON TECHNOLOGY. Supplement to the President's 2019 Budget request submitted to Congress on February 12, 2018. Product of the Subcommittee on Nanoscale Science, Engineering, and technology. EUA: National science and technology Council, 2018.

VAN TASSEL, Katherine. Regulating in Uncertainty: Animating the Public Health Product Safety Net to Capture Consumer Products Regulated by the FDA that Use Innovative Technologies, Including Nanotechnologies, Genetic Modification, Cloning, and Lab Grown Meat. University of Chicago Legal Forum, [s.v./s.n.], p. 433-488, 2013.

VARELLA, Marcelo Dias Varella; BARROS-PLATIAU, Ana Flávia. Organismos Geneticamente Modificados. Belo Horizonte: Del Rey, 2005.

Recebido em: 14 jan. 2019.

Aceito em: 28 jun. 2019. 